Cahiers $d u$ MONDE RUSSE

\section{Cahiers du monde russe}

Russie - Empire russe - Union soviétique et États indépendants

45/3-4 | 2004

Varia

Grigorij M. Bongard-Levin, Roland Lardinois, Aleksej A. Vigasin, eds., Correspondances orientalistes entre Paris et Saint-Pétersbourg (1887-1935)

\title{
Alain Blum
}

\section{(2) OpenEdition}

Journals

Édition électronique

URL : https://journals.openedition.org/monderusse/4188

DOI : $10.4000 /$ monderusse.4188

ISSN : $1777-5388$

Éditeur

Éditions de l'EHESS

Édition imprimée

Date de publication : 1 juillet 2004

Pagination : 663-664

ISBN : 2-7132-2009-2

ISSN : $1252-6576$

Référence électronique

Alain Blum, " Grigorij M. Bongard-Levin, Roland Lardinois, Aleksej A. Vigasin, eds., Correspondances orientalistes entre Paris et Saint-Pétersbourg (1887-1935) », Cahiers du monde russe [En ligne], 45/3-4 | 2004, mis en ligne le 02 juin 2009, consulté le 04 septembre 2022. URL : http://

journals.openedition.org/monderusse/4188; DOI : https://doi.org/10.4000/monderusse.4188

Ce document a été généré automatiquement le 4 septembre 2022.

Tous droits réservés 


\title{
Grigorij M. Bongard-Levin, Roland Lardinois, Aleksej A. Vigasin, eds., Correspondances orientalistes entre Paris et Saint-Pétersbourg (1887-1935)
}

\author{
Alain Blum
}

\section{RÉFÉRENCE}

Grigorij M. BONGARD-LEVIN, Roland LARDINOIS, Aleksej A. VIGASIN, eds.,

Correspondances orientalistes entre Paris et Saint-Pétersbourg (1887-1935). Paris, Académie des inscriptions et belles-lettres, Diff. de Bocard, 2002, 305 p. (Mémoires de l'Académie des inscriptions et belles-lettres, 26)

1 Cet ouvrage est le résultat d'une initiative que l'on ne peut que saluer. Il s'agit de la publication d'une correspondance scientifique entre les milieux orientalistes français et russe, portant sur une période cruciale pour les relations scientifiques internationales, tant du point de vue politique (Première Guerre mondiale, révolution russe et grand tournant stalinien), que de celui de l'histoire des sciences (période du développement de l'orientalisme, en particulier en Asie centrale). Il s'agit essentiellement de la correspondance, retrouvée dans les archives de l'Académie des sciences, entre Sylvain Lévi et Sergej Ol'denburg. Elle est malheureusement à sens unique, puisqu'on ne dispose pas, à quelques exceptions près, des lettres réceptionnées du côté français (sans doute sont-elles perdues), mais uniquement de celles qui furent reçues par les Russes de leurs interlocuteurs français. Outre ces lettres écrites par Lévy à ol'denburg, le recueil en comporte quelques-unes échangées entre Alfred Foucher, Émile Senart et Paul Pelliot d'un côté, et d'autres homologues russes, Ščerbatskoj, Alekseev, Radlov et Rozenberg, personnalités reconnues d'un orientalisme qui porte un intérêt particulier aux langues, à 
l'archéologie et à l'histoire de l'Asie centrale. Comme le souligne la présentation, «trois univers de savoirs les réunissent: d'une part la connaissance des langues et des littératures indo-européennes rares (comme le tokharien), d'autre part, celle des langues et des littératures turco-mongoles (comme l'ouïgour) et, enfin, l'étude du bouddhisme et l'histoire de sa diffusion en Extrême-Orient. "

2 L'ensemble est précédé d'une préface rédigée par les trois coéditeurs, érudite et précise, replaçant les intervenants tant dans leur propre parcours que dans ce milieu spécifique, et montrant comment ils progressent, à partir des textes dont ils disposent, mais aussi à travers des missions de longue durée. La préface évoque aussi les formes d'une circulation intellectuelle, la constitution de réseaux d'orientalistes, les lieux de vie propres à chacun permettant de mieux comprendre leur environnement proche. Elle ébauche ainsi un panorama d'un monde intellectuel très particulier qui franchissait les frontières tout en restant fortement ancré dans un cercle national. Le milieu international, tel qu'il ressort de ces lettres, est autant fait de relations étroites que de concurrence acharnée pour traduire et publier certains manuscrits. Il repose aussi sur un internationalisme qui n'est pas exempt, loin s'en faut, de réactions aux événements politiques du moment, comme le refus de travailler avec les Allemands après la Première Guerre mondiale, exprimé notamment par Sylvain Lévi en termes particulièrement hostiles.

3 La correspondance elle-même exprime toute cette richesse. Elle montre d'abord des relations scientifiques qui s'entremêlent avec des relations d'amitié, dans un même mouvement. Chaque lettre, en particulier celles de Lévi à Ol'denburg, passe allègrement de considérations privées, d'informations sur des connaissances communes, le plus souvent amicales, à des indications sur un travail scientifique (à propos de tel ou tel texte) ou des informations sur un voyage. Les textes scientifiques sont bien au centre des préoccupations de nombreuses lettres. Les observations politiques ne sont pas absentes, celles d'un quotidien qui précède la Première Guerre mondiale où la circulation n'est pas facile (Lévi souligne la difficulté d'obtenir un passeport en 1913, en sa qualité de juif) ; celle d'un premier conflit mondial qui heurte le rêve internationaliste des savants, mais les conduit aussi, on l'a noté, à une hostilité vis-à-vis des Allemands qui se prolonge bien au-delà de la fin du conflit; celle de la révolution russe et des années qui suivent, peu présentes et très discrètement évoquées dans une lettre de Lévi à Ol'denburg, en novembre 1929, après l'éviction de ce dernier de son poste de secrétaire de l'Académie des sciences de l'URSS - lettre discrète qui montre la prudence imposée, très vite, dans ces correspondances après la révolution. D'autres éléments politiques sont présents, liés au jubilé de l'Académie des sciences tenu en 1925 à Leningrad, où Lévi et Pelliot furent invités et firent des interventions dans lesquelles ils affirmaient leur désaccord avec les autorités.

4 Cette correspondance offre donc de multiples pistes pour comprendre le quotidien d'un milieu international, observer comment se nouent des échanges culturels et se constitue une communauté autour de quelques personnalités, attachées par des liens qui dépassent largement la simple dimension scientifique. Cette publication, dont l'appareil de notes est remarquablement précis et développé, est donc une belle contribution à une démarche contemporaine qui s'intéresse aux transferts culturels et à la réalisation d'une sociologie du champ scientifique, non pas simplement par l'intermédiaire de la circulation des idées, textes et échanges formels, mais à travers l'analyse du quotidien. 
On ne peut encore une fois que se féliciter d'une telle entreprise et de sa publication dans une collection érudite et de grande qualité. 